\title{
Processo e Procedimento Administrativo Disciplinar Militar: Necessidade de ampliação dos encarregados de sindicância e de procedimento investigatório preliminar no âmbito da Polícia Militar do Estado do Tocantins
}

\author{
Military Disciplinary Administrative Process and Procedure: Need to expand the heads of \\ investigation and preliminary investigative procedure within the scope of the Military Police of the
}

State of Tocantins

Proceso y Procedimiento Administrativo Disciplinario Militar: Necesidad de ampliar los jefes de investigación y procedimiento de instrucción preliminar en el ámbito de la Policía Militar del Estado de Tocantins

Recebido: 11/07/2021 | Revisado: 16/07/2021 | Aceito: 18/07/2021 | Publicado: 26/07/2021

\author{
Philipe Lira de Carvalho \\ ORCID: https://orcid.org/0000-0002-4778-4274 \\ Polícia Militar do Estado do Tocantins, Brasil \\ E-mail: lirapmto@gmail.com \\ Frank Cynatra Sousa Melo \\ ORCID: https://orcid.org/0000-0001-8824-6811 \\ Polícia Militar do Estado do Tocantins, Brasil \\ E-mail: frankcynatra@gmail.com \\ José Carlos da Costa Abreu \\ ORCID: https://orcid.org/0000-0002-0332-8402 \\ Polícia Militar do Estado do Tocantins, Brasil \\ E-mail: cad.abreu@hotmail.com
}

\begin{abstract}
Resumo
O presente trabalho científico tem por objetivo analisar os processos e procedimento administrativos disciplinar, com ênfase ao que ocorre no âmbito da Polícia Militar do Estado do Tocantins - PMTO, com vistas à ampliação dos policiais militares encarregados $\left(1^{\circ}\right.$ Sargentos aperfeiçoados e Subtenentes do Quadro combatente) de Sindicância e de Procedimento Investigatório Preliminar - PIP. Consoante a Constituição Federal de 1988, o processo administrativo disciplinar é obrigatório para apuração de condutas e possível aplicação de penalidades. Dessa forma, no Estado do Tocantins é através da Lei n. 2578 (2012), bem como pelo Decreto n. 4994 (2014), que versam sobre os processos administrativos para apurar as condutas dos integrantes militares estaduais. Além da Instrução Normativa n. 001/2014 - Gabinete do Comandante-Geral que instituiu o PIP na PMTO. Destaca-se que os processos administrativos disciplinares no âmbito militar são importantes para a manutenção da hierarquia e disciplina, pois é à base das instituições militares brasileiras. Já a importância do PIP está em apurar os fatos que não tenham indícios suficientes para instauração de Sindicância. Na metodologia do trabalho foi utilizada a pesquisa de natureza aplicada, descritiva, bibliográfica e documental, utilizando-se do método hipotético-dedutivo e realizada uma abordagem qualitativa. No final, concluiu-se que há possibilidade jurídica para que os mencionados graduados no âmbito da PMTO sejam encarregados de sindicância e de PIP, desde que haja alteração em normas.
\end{abstract}

Palavras-chave: Polícia militar; Tocantins; Processo administrativo; Procedimento administrativo.

\begin{abstract}
The present scientific work aims to analyze the disciplinary administrative processes and procedures, with emphasis on what happens within the scope of the Military Police of the State of Tocantins - PMTO, with a view to expanding the military police in charge (1st perfected Sergeants and Sublieutenants of the combatant staff) Investigation and Preliminary Investigation Procedure - PIP. Pursuant to the Federal Constitution of 1988, the administrative disciplinary process is mandatory for investigation of conduct and possible application of penalties. Thus, in the State of Tocantins, through Law n. 2578 (2012), as well as by Decree n. 4994 (2014), which deal with administrative processes to investigate the conduct of state military members. In addition to Normative Instruction No. 001/2014 Office of the General Commander that instituted the PIP in PMTO. It is noteworthy that administrative disciplinary processes in the military sphere are important for the maintenance of hierarchy and discipline, as it is the basis of Brazilian military institutions. The importance of the PIP, on the other hand, is to investigate the facts that do not have sufficient evidence for the establishment of an Inquiry. In the work methodology, applied, descriptive, bibliographical
\end{abstract}


and documentary research was used, using the hypothetical-deductive method and carried out a qualitative approach. In the end, it was concluded that there is a legal possibility for the aforementioned graduates in the scope of the PMTO to be in charge of investigation and PIP, as long as there is a change in the rules.

Keywords: Military police; Tocantins; Administrative process; Administrative procedure.

\section{Resumen}

Este trabajo científico tiene como objetivo analizar los procesos y procedimientos administrativos disciplinarios, con énfasis en lo que sucede en el ámbito de la Policía Militar del Estado de Tocantins - PMTO, con miras a ampliar la policía militar a cargo (Sargentos y Subtenientes 1er perfeccionados de el personal combatiente) Procedimiento de Investigación e Investigación Preliminar - PIP. De acuerdo con la Constitución Federal de 1988, el proceso administrativo disciplinario es obligatorio para la investigación de conductas y la posible aplicación de sanciones. Así, en el Estado de Tocantins, a través de la Ley n. 2578 (2012), así como por el Decreto n. 4994 (2014), que se ocupa de los procesos administrativos para investigar la conducta de militares estatales. Además de la Instrucción Normativa No. 001/2014 - Oficina del Comandante General que instituyó el PIP en PMTO. Es de destacar que los procesos administrativos disciplinarios en el ámbito militar son importantes para el mantenimiento de la jerarquía y la disciplina, ya que es la base de las instituciones militares brasileñas. La importancia del PIP, por otro lado, es investigar los hechos que no tienen evidencia suficiente para establecer una Investigación. En la metodología de trabajo se utilizó la investigación aplicada, descriptiva, bibliográfica y documental, utilizando el método hipotéticodeductivo y se realizó un enfoque cualitativo. Al final, se concluyó que existe la posibilidad legal de que los citados egresados en el ámbito de la PMTO estén a cargo de la investigación y el PIP, siempre y cuando exista un cambio en la normativa.

Palabras clave: Policía militar; Tocantins; Proceso administrativo; Procedimiento administrativo.

\section{Introdução}

Conforme a Constituição da República Federativa do Brasil (1988), a Polícia Militar é uma das Instituições responsável pela Segurança Pública e cabe a ela o exercício do policiamento ostensivo, com o intuito de preservação da ordem pública.

Durante o exercício de suas atividades laborativas, seja no âmbito operacional ou administrativo, os policiais militares se não cumprirem ou excederem no cumprimento dos seus deveres, poderão responder nas esferas administrativa, penal e cível.

O presente trabalho tratou da esfera administrativa que trata sobre o processo e procedimento administrativo, com destaque para o âmbito militar. Então, caso os policiais militares pratiquem transgressões disciplinares, essas condutas irão acarretar o poder/dever da instituição militar de apurar os fatos e punir administrativamente seus integrantes, caso seja comprovado à ilicitude.

De acordo com a Constituição do Brasil (1988), no artigo 41, para aplicar penalidades que acarretem perda de cargo ao servidor público estável, é necessário que se tenha o processo administrativo, sendo assegurado o contraditório e a ampla defesa. Nesse diapasão, quando ocorre transgressão praticada pelo servidor, a administração deve a apurar o fato que chegou ao seu conhecimento, utilizando como instrumento o processo administrativo disciplinar.

Nas polícias militares não são diferentes, cada Corporação tem seu regulamento disciplinar próprio que tratam dos processos adotados no caso de cometimento de transgressões disciplinares pelos seus integrantes.

Diante do exposto, a Polícia Militar do Estado do Tocantins - PMTO como as demais instituições militares brasileiras, está fundamentada nos princípios da hierarquia e disciplina. Nesse sentido, é através do processo administrativo disciplinar militar que se apuram as condutas dos seus integrantes para avaliar as condições morais e profissionais. Ou até mesmo, por meio do Procedimento Investigatório Preliminar - PIP, que poderá ser levantado indícios de possíveis atos transgressivos, subsidiando a instauração de processo administrativo.

No Estado do Tocantins, é o Estatuto dos Policiais Militares e Bombeiros Militares do Estado do Tocantins (Lei n. 2578, 2012) e o Regulamento Disciplinar dos Militares Estaduais do Tocantins - RDMETO (Decreto n. 4994/2014) que regulam os processos administrativos militares. E a Instrução Normativa n. 001/2014 - Gabinete do Comandante-Geral (Polícia 
Militar do Estado do Tocantins [PMTO], 2014) que instituiu e regulamenta o PIP.

No rol dos os processos administrativos militares (gênero) estabelecidos no Estado do Tocantins, enfatiza-se que a sindicância (espécie) é o instrumento utilizado pela administração castrense para investigar as supostas transgressões disciplinares praticadas por seus integrantes ou para apurar eventual direito.

Além disso, existem também os Conselhos Justificação e de Disciplina que se destinam analisar o aspecto ético e disciplinar do militar para apurar se este ainda pode permanecer no serviço ativo da corporação, com direito ao devido processo legal.

Por fim, o Procedimento Investigatório Preliminar, o qual foi criado na PMTO com a finalidade de subsidiar decisão de Instauração de Sindicância ou Inquérito Policial Militar - IPM.

Nesse aspecto, esta pesquisa é muito importante do ponto de vista social, profissional, institucional e jurídico, pelos seguintes motivos:

$\checkmark \quad$ No âmbito social porque a sociedade tem/enxerga a PMTO como um importante órgão garantidor dos Direitos Humanos. Logo, quanto maior o número de profissionais capacitados e encarregados para atuação nos processos e procedimento administrativos, mais celeridade haverá na resolução das demandas que são de interesses social e institucional;

$\checkmark \quad$ No âmbito profissional porque os $1^{\circ}$ Sargentos aperfeiçoados e Subtenentes da PMTO ao poderem atuar como encarregados de processos administrativos deverão receber mais capacitações e contribuirão ainda mais com as demandas administrativas da instituição;

$\checkmark \quad$ No âmbito institucional porque ao ampliar o rol dos encarregados para os processos administrativos se tornará mais eficiente/eficaz na resolução das demandas de interesse institucional e da sociedade;

$\checkmark \quad$ Do ponto de vista jurídico, esta pesquisa corrobora as legislações sobre processo e procedimento administrativo disciplinar.

Isto posto, a presente pesquisa teve como objetivo geral analisar o processo e procedimento administrativo disciplinar, dando ênfase ao que ocorre no âmbito da Polícia Militar do Estado do Tocantins, com vistas à ampliação dos encarregados desses instrumentos administrativos de apuração, Sindicância e PIP, respectivamente.

O problema estudado partiu-se da pergunta norteadora se há possibilidade jurídica dos $1^{\circ}$ Sargentos aperfeiçoados e Subtenentes da PMTO serem encarregados de processos e procedimento administrativos? Partiu-se da hipótese que sim, desde que haja mudança legislativa na Lei Estadual Castrense n. 2578 (2012), concedendo-lhes tal atribuição no caso da Sindicância e mudança em Instrução Normativa da Corporação para o caso do PIP.

Para alcançar o objetivo geral, foram delineados os seguintes objetivos específicos ao longo das seções da pesquisa:

$\checkmark \quad$ Descrever sobre o processo administrativo;

$\checkmark \quad$ Apresentar o processo administrativo disciplinar;

$\checkmark \quad$ Analisar o Procedimento Investigatório Preliminar;

$\checkmark \quad$ Discorrer sobre a carreira de praças da PMTO; e

$\checkmark \quad$ Identificar algumas instituições militares brasileiras em que seus graduados (sargentos e subtenentes) são encarregados de processos administrativos.

Nesse sentido, para uma melhor compreensão, presente o trabalho científico foi dividido na seguinte forma: metodologia, resultados e discussão e considerações finais.

\section{Metodologia}

Para o desenvolvimento deste trabalho científico, foi utilizada a pesquisa de natureza aplicada, após o levantamento da problemática, podem ser aplicados novos conhecimentos sobre o conteúdo com possiblidade de aplicação prática na Polícia 
Militar do Estado do Tocantins, uma vez que foram levantadas situações verídicas (Silveira \& Córdova, 2009).

Quantos aos objetivos, a pesquisa se enquadra como descritiva, uma vez que foram descritas características de fatos e fenômenos de determinada realidade, por meio de uma série de informações pesquisadas (Fontana, 2018).

Em relação aos procedimentos foi realizada a pesquisa bibliográfica e documental, por meio de levantamentos bibliográficos e análise de documentos da Corporação.

O estudo utilizou-se o método hipotético-dedutivo, pois a abordagem inicial se deu através de uma lacuna nos conhecimentos, na qual foi formulada hipóteses e se desencadeou a influência dedutiva para testar a predição da ocorrência dos fenômenos estudados (Marconi \& Lakatos, 2016).

Além disso, utilizou-se de abordagem qualitativa, a qual conforme Fontana (2018) atende aos componentes de determinada situação, bem como suas interações recíprocas e influências com determinada visão. De maneira que proporcionou interpretações de normas que estão relacionados com a temática da pesquisa.

Finalmente, este trabalho técnico-científico foi desenvolvido através de pesquisa documental, uma vez que foram pesquisados documentos e normas que versam sobre o tema estudado (Mazucato, 2018).

\section{Resultados e Discussão}

Sabe-se que os atos da administração pública são realizados por meio de processos, pois é a base para que o Órgão Público possa proporcionar respostas aos seus administrados.

Consoante os ensinamentos de Sousa (2015, p. 32) "o processo administrativo é o conjunto de atos adotados em qualquer procedimento realizado pela Administração, com o objetivo de documentar e instruir a tomada de decisões, sejam elas de contratar ou de punir."

Portanto, os atos realizados na administração devem ser processados e documentados com o objetivo de que a autoridade pública possa tomar decisões, aplicar penalidade, garantir direitos, dentre outros.

O autor em epígrafe ainda descreve que o processo visa controlar a conduta dos administrados e tem o condão de solucionar os conflitos entre a administração e seus agentes (Sousa, 2015).

Já para doutrinador Manoel (2008) o processo é conjunto de atos coordenados para dizer o direito no caso concreto, que observa os princípios do devido processo legal (competência, finalidade, formalidade e legalidade), da ampla defesa e do contraditório. Por sua vez o procedimento é a forma de proceder, de realizar os atos de investigação; diz-se do feito inquisitorial, investigatório, onde não há o contraditório e a ampla defesa, em função da ausência do acusado; é a forma de andamento do processo (Manoel, 2008).

Na Polícia Militar do Estado do Tocantins, os processos e procedimentos podem ser divididos em 2 (dois) grandes grupos: 1) aqueles derivados do exercício das funções de Polícia Judiciária Militar, que busca a investigação dos ilícitos penais militares; e 2) aqueles derivados do Poder Disciplinar da Administração Pública, que é a faculdade da Administração Pública de controlar o desempenho das funções e a conduta de seus servidores.

Derivados do exercício da função de Polícia Judiciária Militar têm-se apenas procedimentos, que são o Inquérito Policial Militar (IPM) e o Auto de Prisão em Flagrante Delito (APFD). Já em ralação aos derivados do Poder Disciplinar, na PMTO têm-se 3 (três) processos e 01 (um) procedimento, demonstrados na tabela, a seguir: 
Tabela 1 - Processos e Procedimento derivados do Poder Disciplinar.

\begin{tabular}{|l|c|}
\hline \multicolumn{2}{|c|}{ Poder Disciplinar } \\
\hline \multirow{2}{*}{ Processo } & Conselho Disciplinar \\
\cline { 2 - 2 } & Conselho de Justificação \\
\cline { 2 - 2 } Procedimento & Procedimento Investigatório Preliminar \\
\hline
\end{tabular}

Fonte: Autores (2021).

Os processos administrativos militares estão positivados através do Estatuto dos Policiais Militares e Bombeiros Militares do Estado do Tocantins (Lei n. 2578, 2012) e regulado pelo Regulamento Disciplinar dos Militares Estaduais do Tocantins - RDMETO (Decreto n. 4994, 2014). E o Procedimento Investigatório Preliminar foi instituído na PMTO pela Instrução Normativa n. 001/2014 - Gabinete do Comandante-Geral (PMTO, 2014).

Nos ensinamentos de Di Pietro (2019), o processo administrativo disciplinar é obrigatório, pois tem previsão legal no artigo 41 do texto constitucional para a aplicação das penalidades que acarretem a perda de cargo para o servidor público estável.

Consoante Meireles (2006), o processo administrativo disciplinar é a forma punição ou de apuração das faltas graves de todos os servidores públicos e das pessoas submetidas ao regime funcional de determinados estabelecimentos da administração pública.

Nesse contexto, o processo administrativo disciplinar utiliza-se do poder disciplinar que é estabelecido à administração com o objetivo de aplicar sanções aos seus administrados que praticarem irregularidades. Ademais, o processo administrativo disciplinar deve ser instaurado quando se tiver indícios suficientes de autoria e materialidade, pois somente no processo que o acusado poderá se defender contra os fatos que lhe são imputados.

Para que o processo administrativo tenha andamento, a autoridade legal delega ao servidor/encarregado de instruir todo processo, e cabe-lhe a feitura garantindo que ambas as partes exerçam - em sua plenitude - os seus respectivos direitos. No final, deverá opinar no sentido de propiciar ao julgador, todos os elementos necessários para uma decisão (Bianchinni, 2010).

A Constituição ao discorrer sobre o processo administrativo no tópico dos Direitos e Garantias Fundamentais, no artigo $5^{\circ}$, inciso LIV, positivou que "ninguém será privado da liberdade ou de seus bens sem o devido processo legal." (Constituição do Brasil, 1988). Assim, a constituição cidadã deu garantias para que todo cidadão não tenha sua liberdade cerceada ou seus bens confiscados sem o devido processo legal.

O texto constitucional brasileiro ainda descreve os princípios que devem ser resguardados no processo administrativo artigo $5^{\circ}$, inciso LV, o qual estabelece que "aos litigantes, em processo judicial ou administrativo, e aos acusados em geral são assegurados o contraditório e ampla defesa, com os meios e recursos a ela inerentes" (Constituição do Brasil, 1988).

De acordo com Assis (2012), o Direito Administrativo Disciplinar Militar é o Estado se manifestando no abalizamento de conduta dos integrantes das instituições militares com a pretensão uma melhor prestação de serviço no alcance das missões constitucionalmente fixadas para as forças armadas e auxiliares. Portanto, tal manifestação se efetiva por meio do processo administrativo disciplinar militar.

Nos entes federativos brasileiros o processo administrativo disciplinar militar aparece regulado pelos regulamentos disciplinares que são normas infraconstitucionais. No Estado do Tocantins, esse processo está normatizado através da Lei $\mathrm{n}$. 2578 (2012), no capítulo dos processos administrativos disciplinares, artigo 50, caput, in verbis:

Art. 50. São processos administrativos disciplinares no âmbito da Corporação: 
I - a sindicância;

II - os Conselhos de Justificação ou de Disciplina.

Dependendo do tipo de transgressão, haverá o instrumento adequado para apuração. Dessa forma, na PMTO, caso o policial militar pratique condutas ilícitas de menor gravidade, caberá apuração por meio da sindicância que é uma espécie do processo administrativo disciplinar.

A transgressão disciplinar na administração castrense do Tocantins é tratada no artigo 42, caput, que diz “Transgressão disciplinar é a infração administrativa caracterizada pela violação aos preceitos ou deveres da ética inerentes à atividade militar, incorrendo o autor nas sanções previstas nesta Lei” (Lei n. 2578, 2012). Posto isso, a transgressão disciplinar é caracterizada quando ocorrem condutas administrativas ilícitas que estão tipificadas na norma em comento. Caso o tipo de transgressão praticada esteja tipificado no artigo 57 da lei em epígrafe, o instrumento de investigação para avaliar se o transgressor tem a capacidade de permanecer na instituição, será feito pelo Conselho de Disciplina (nos assuntos que envolvem praça) ou por Conselho de Justificação (nos assuntos que envolvem oficial).

Ademais, na aludida legislação castrense, em seu artigo 13, inciso V, diz que "a pena de demissão é aplicada ao militar não estável, após sindicância, e, ao estável, após submissão a Conselho de Justificação ou de Disciplina” (Lei n. 2578, 2012).

De acordo com o texto constitucional, no caput do artigo 42, os integrantes estaduais das polícias militares e dos corpos de bombeiros militares são organizados com base na hierarquia e disciplina que são as vigas mestres das organizações militares, que constitui matéria de ordem constitucional (Constituição do Brasil, 1988).

Portanto, a hierarquia e a disciplina demostram os principais atributos da relação profissional, no qual são manifestados pelo dever de obediência e subordinação e que se prolonga de forma duradoura a todas as conjunturas da vida entre militares.

Conforme as lições de Carvalho Filho (2014), a hierarquia é o ordenamento vertical dos órgãos e agentes da Administração e tem por objetivo a organização da função administrativa. Ainda conforme o autor, a disciplina consiste no respeito que os servidores da administração pública devem ter para as normas no qual estão sujeitos, devendo cumprir seus deveres e obrigações que são requisitados e fiscalizados pelos superiores hierárquicos.

Visto que a hierarquia e a disciplina são as bases institucionais das polícias militares brasileiras, no artigo 13 da Lei em alusão descreve que:

Art. 13. A hierarquia e a disciplina são a base institucional da Polícia Militar e do Corpo de Bombeiros Militar, e a autoridade e a responsabilidade crescem com o grau hierárquico.

$\S 1^{\circ}$ A hierarquia militar consiste na ordenação da autoridade em níveis diferenciados, dentro da estrutura da Corporação. [...]

$\S 3^{\circ} \mathrm{O}$ respeito à hierarquia é consubstanciado no espírito de acatamento à sequência de autoridade.

$\S 4^{\circ}$ Disciplina é a rigorosa observância e o acatamento integral das leis, regulamentos, normas e disposições que fundamentam a Corporação e coordenam o seu funcionamento regular e harmônico, traduzindo-se pelo perfeito cumprimento do dever por parte de todos e cada um de seus integrantes.

$\S 5^{\circ} \mathrm{A}$ disciplina e o respeito à hierarquia devem ser mantidos em todas as circunstâncias da vida entre militares da ativa, da reserva remunerada, reformados e de outras organizações militares. [...] (Lei n. 2578, 2012).

Conforme o exposto, frisa-se que a hierarquia e disciplina são valores importantes. Assim como nos demais estados da federação, estão também positivadas em norma do Estado do Tocantins e devem ser preservadas e fortalecidas por todos policiais e bombeiros militares tocantinenses, pois esses profissionais são os representantes da garantia da lei e da ordem, devendo pautar suas condutas pela observância aos preceitos legais, morais e éticos.

No âmbito tocantinense, a sindicância tem previsão legal na Lei n. 2578 (2012), artigo 50, inciso I, regulada através 
do Decreto n. 4994/2014, o qual foi criado com o objetivo de regulamentar o processo administrativo disciplinar no âmbito da administração militar estadual do Tocantins. Sabe-se que Estado possui o poder/dever de aplicar punição aos agentes públicos que praticarem atos ilícitos, sempre observando o devido processo legal, o contraditório e a ampla defesa.

Nesse diapasão, a sindicância é o instrumento para apuração de condutas dos integrantes - e acarreta demissão dos membros não estáveis - e também tem o condão de apurar eventuais direitos dos militares, por exemplo, promoção por bravura.

Nos processos administrativos disciplinares militar tocantinense, nos casos em que não se tem indícios suficientes para a abertura ou quando houver a necessidade de identificação do policial militar envolvido em eventual infração, é aberto primeiramente o Procedimento Investigatório Preliminar (PIP) para que se apurem os fatos. No caso se houver indícios de infração, abre-se a sindicância ou outro instrumento de apuração correspondente (PMTO, 2014).

As autoridades competentes para instaurar determinar a abertura de sindicância no âmbito da PMTO, estão dispostas no artigo 40 da Lei n. 2578 (2012), que estabelece o Chefe do Poder Executivo Estadual, o Comandante-Geral, o Chefe do Estado Maior, o Corregedor-Geral, o Secretário-Chefe e o Subchefe da Casa Militar, o Diretor, o Subdiretor, o Chefe de Seção do Estado Maior, os Comandantes ou Subcomandantes de UPM, dentre outros.

Com relação aos policiais militares tocantinenses que podem ser designados para serem encarregados de sindicância no âmbito da PMTO, está positivado na legislação em epígrafe, no artigo 54, que "Podem ser designados Sindicantes os Oficiais ou Aspirantes a Oficial, a critério da autoridade instauradora, respeitada a hierarquia" (Lei n. 2578, 2012).

Portanto, somente os Oficiais e os Aspirantes a Oficial podem ser designados como encarregados de Sindicância, já o graduado só poderá funcionar como escrivão no referido processo administrativo em que o encarregado for um Oficial Superior.

Os atos da sindicância devem seguir a sequência que foi determinada pela Lei n. 2578 (2012), no caput, do Artigo 52, que assim descreve:

Art. 52. As peças da sindicância devem ser escritas, numeradas e rubricadas pelo sindicante, obedecida a seguinte ordem cronológica: I - instauração; II - autuação; III - citação do sindicado; IV - interrogatório do sindicado; V defesa preliminar em três dias úteis; VI - instrução; VII - alegações finais em cinco dias úteis; VIII - relatório do Sindicante; IX - solução; X - enquadramento, quando violada a norma sancionadora.

Conforme o artigo 13, $\S 6^{\circ}$, inciso VI, da Lei n. 2578 (2012), da Sindicância poderá resultar as seguintes punições em ordem de gravidade crescente: advertência, repreensão; detenção, prisão, reforma disciplinar e demissão. Dessa forma, a sindicância pode resultar desde uma advertência, podendo chegar até uma demissão do militar estadual tocantinense (se não for estável). Contudo se o militar for estável, só poderá ser demitido após submissão do Conselho de Justificação ou de Disciplina (Lei n. 2578, 2012).

Consoante está disposto na Constituição do Brasil (1988), em seu artigo 41, a administração pública que deve instaurar o processo administrativo disciplinar para a aplicação das penalidades que impliquem perda de cargo para o funcionário estável, a saber:

Art. 41. São estáveis após três anos de efetivo exercício os servidores nomeados para cargo de provimento efetivo em virtude de concurso público.

$\S 1^{\circ} \mathrm{O}$ servidor público estável só perderá o cargo:

I - em virtude de sentença judicial transitada em julgado;

II - mediante processo administrativo em que lhe seja assegurada ampla defesa.

Posto isso, em cumprimento ao mandamento legal, a Administração Militar do Estado do Tocantins dispõe da Lei n. 
2578 (2012), no seu artigo 55, que trata sobre os Conselhos de Justificação e de Disciplina e tem o condão de apreciar a capacidade ética e disciplinar do militar que tenha estabilidade (se pode continuar no serviço ativo da Corporação), observando o devido processo legal.

Dessa forma, os Conselhos de Justificação e de Disciplina da PMTO visam apurar condutas ilícitas possivelmente praticadas pelos militares tocantinenses e que podem afastá-los do serviço. O Conselho de Justificação é aplicado ao Oficial e o de Disciplina é aplicado à praça.

É importante mencionar que as situações que ensejam a abertura de Conselho de Justificação e de Disciplina aos militares estaduais tocantinenses estão previstas no artigo 57 da Lei n. 2578 (2012), no qual está elencado uma gama de atos de natureza grave.

$\mathrm{Na}$ administração tocantinense, somente o Chefe do Poder Executivo, o Comandante-Geral, o Chefe do Estado Maior na falta ou impedimento deste e o Secretário Chefe da Casa Militar são as autoridades competentes para instauração do Conselho de Justificação e de Disciplina.

Ademais, na incumbência do Conselho de Disciplina pode ser designado um graduado e no Conselho de Justificação somente os Oficiais, observando sempre a precedência hierárquica sobre o militar a ele submetido, todos os membros com direito a voto (Lei n. 2578, 2012).

O Artigo 60, da aludida legislação tocantinense, os Conselhos de Justificação ou de Disciplina no Estado do Tocantins estabelece o rito que deve ser seguido.

Consoante o artigo 62, caput, da Lei n. 2578 (2012), ao final do Conselho propõe-se as seguintes medidas:

I - instauração de Inquérito Policial Militar - IPM, se houver indícios de crime militar;

II - encaminhamento de documentos à autoridade policial competente quando houver indícios de cometimento de infração penal de natureza comum;

III - reforma nos termos desta Lei;

IV - transferência para a reserva remunerada proporcional, se considerado inabilitado definitivamente para inclusão nos quadros de acesso para promoção, na forma desta Lei;

V - demissão;

VI - aplicação de qualquer outra sanção disciplinar prevista nesta Lei, que não a demissão;

VII - arquivamento.

Então, observa-se que são 07 (sete) as medidas previstas no dispositivo que trata sobre o resultado dos Conselhos, podendo ter uma medida de arquivamento até uma punição de demissão do serviço militar do Estado do Tocantins.

O Procedimento Investigatório Preliminar- PIP surgiu na PMTO em virtude da extinção da antiga Sindicância Sumária e com o advento do Regulamento Disciplinar dos Militares Estaduais do Tocantins - RDMETO em seu:

Art. 175. Ao respectivo Comandante-Geral de cada Corporação Militar Estadual compete estabelecer Instruções Normativas complementares necessárias à orientação e aplicação deste Regulamento Disciplinar.

Parágrafo Único. Compete ao Comandante-Geral estabelecer e regulamentar procedimentos investigatórios sem fins punitivos no âmbito da respectiva Corporação (Decreto n. 4994, 2014).

Diante disso, verificou-se que o Comandante-Geral ficou encarregado da criação desse Procedimento, o qual foi instituído pela Instrução Normativa - IN n. 001/2014 - Gabinete do Comandante-Geral na data de 12 de março de 2014.

Em conformidade com a referida Instrução Normativa, o PIP é um procedimento administrativo que foi criado na PMTO com a finalidade de subsidiar decisão de Instauração de Sindicância ou Inquérito Policial Militar - IPM (Polícia Militar do Estado do Tocantins [PMTO], 2014)

O PIP é regido pelos princípios da celeridade, economia processual, informalidade e simplicidade e ainda possui as 
seguintes características: 1) ausência de ampla defesa e contraditório; 2) não é publicada; 3) não é transcrita na ficha individual de alterações do militar investigado; 4) não gera punição disciplinar; 5) não cabe prorrogação; 6) apura somente a existência de indícios; 7) dentre outras (PMTO, 2014).

A conclusão do PIP deve ocorrer em 20 (vinte) dias, prazo esse improrrogável, podendo haver a suspensão do prazo pelos mesmos motivos que podem haver na Sindicância, com base no art. 21, da referida Instrução (PMTO, 2014). Ademais o PIP tem um rito bem mais simples e célere que os Processos Administrativos.

Ainda segundo a Instrução Normativa em questão em seu:

Art. $7^{\circ}$ Podem ser designados encarregados do PIP:

I - Oficial, sendo superior hierárquico ou mais antigo que o investigado;

II - Aspirante a Oficial, quando o fato a apurar envolva somente praças com graduações inferiores a Subtenente.

III - no caso de afastamento do encarregado do PIP, outro oficial ou aspirante a oficial é designado imediatamente, não havendo suspensão ou interrupção de prazo (PMTO, 2014).

Portanto, assim como a Sindicância, o PIP atualmente só pode ter como encarregado Oficiais ou Aspirantes a Oficial, respeitada a antiguidade entre o Encarregado e o Investigado.

A Constituição do Brasil (1988), no artigo 37, inciso II, impõe que para ingresso em cargo ou emprego público é necessário aprovação em concurso público. Isto posto, para ingressar em qualquer um dos quadros da PMTO é preciso que o (a) candidato (o) seja aprovado em concurso público.

Consoante estabelece a Lei n. 2578 (2012), no seu artigo 11, diz que:

Art. 11. O ingresso na Corporação depende da aprovação em concurso público de provas ou de provas e títulos, com aplicação de exame de conhecimentos e habilidades, exame de capacidade física, avaliação de saúde e psicológica e exame toxicológico, na forma prevista nesta Lei e no correspondente edital.

Nesse aspecto, observa-se além da aprovação na prova escrita do concurso público, há uma série de requisitos para o ingresso na carreira de praças da PMTO. Em alguns dos requisitos, o militar deverá cumprir o interstício (tempo mínimo de permanência na graduação) e realizar obrigatoriamente os cursos que estão dispostos na Lei n. 2575 (2012) (que dispõe sobre as promoções na Polícia Militar do Estado do Tocantins). Situações estas descritas no artigo 39, da Lei n. 2575 (2012), "Icursos; II- serviço arregimentado; III - exercício de função específica. [...]".

Portanto, para ascender na carreira, as praças devem cumprir esses requisitos e em principal devem ser aprovas nos cursos em que forem matriculados específicos para promoção.

Importante ressaltar que em relação ao Curso de Aperfeiçoamentos de Sargentos apenas os $1^{\circ}$ Sargentos do Quadro de Praças Policiais Militares - QPPM podem fazer conforme Art. 62, V, a, da Lei n. 2578 (2012). Portanto, que se fala de $1^{\circ}$ Sargentos Aperfeiçoados, logo se sabe, que se trata de $1^{\circ}$ Sargentos do QPPM que realizaram o CAS.

Na última matriz curricular do Curso de Formação de Soldados - CFSD/PMTO, tem-se a área de estudo na área jurídica, as seguintes disciplinas e cargas horárias: Noções de Direito Constitucional e Administrativo (30h/a); Noções de Direito Penal Aplicado e Penal Militar (40h/a); Noções de Direito Processual Penal Aplicado e Processual Penal Militar; Direitos Humanos e Cidadania (20h/a); Direito da Infância e da Juventude (20h/a) e Legislação Especial Penal (20h/a) (PMTO, 2014).

Por sua vez, na matriz curricular do Curso de Habilitação de Cabos - CHC, têm-se as seguintes disciplinas e carga horária: Direito Constitucional (10h/a); Direito da Criança e do Adolescente (10h/a); Direito Penal e Direito Penal Militar (20h/a); Direitos Humanos (10h/a), Legislação Especial (10h/a) e Legislação Militar (10h/a) (PMTO, 2010).

Outrossim, na matriz curricular do Curso de Habilitação de Sargentos - CHS, tem-se a área de estudo de Cultura 
Jurídica que tem as seguintes disciplinas e carga horária: Direito Penal e Processual Penal Comum (20h/a); Direito Penal e Processual Penal Militar e Polícia Judiciária (25h/a); Direitos Humanos (10/a); Direito Administrativo (10h/a); Legislação Especial (10h/a) e Legislação Institucional (17h/a) (PMTO, 2006).

Ademais, na mais recente matriz curricular do Curso de Aperfeiçoamento de Sargentos - CAS, para chegar a última graduação, ou seja, Subtenente, possui as disciplinas voltadas aos processos e procedimentos administrativos derivados das funções de Polícia Judiciária Militar e do Poder Disciplinar da Administração Pública, quais sejam: Processos e Procedimentos Administrativos - I (30h/a); Processos e Procedimentos Administrativos - II (30h/a) e Legislação Institucional (30h/a) (PMTO, 2020). Na ementa das referidas disciplinas engloba os processos e procedimentos administrativos citados no corpo deste trabalho, acrescentado Inquérito Policial Militar, Auto de Prisão em Flagrante e Deserção.

Finalmente, para se chegar à última graduação (Subtenente QPPM) da carreira de praças, o $1^{\circ}$ Sargento terá que cumprir todos os requisitos exigidos na norma, entre eles o Curso Aperfeiçoamento de Sargentos (CAS). No qual, em sua formatação já vem capacitando os $1^{\circ}$ Sargentos e Subtenentes a atuarem como escrivães nos Processos e Procedimentos Administrativos da Corporação.

No âmbito federal têm-se as Instruções Gerais para a elaboração de Sindicância no âmbito do Exército Brasileiro (EB10-IG-09.001) e no caput do seu art. 20 está disposto que "O sindicante será oficial, aspirante a oficial, subtenente ou sargento aperfeiçoado, de maior precedência hierárquica que o Sindicado" (Brasil, 2012).

Conforme o exposto, na legislação da força de defesa do país, os graduados: Subtenentes e Sargentos aperfeiçoados, desde o ano de 2012 já são encarregados de instruir Sindicância.

Na Polícia Militar do Estado de Amapá [PMAP] (2001), os Subtenentes da Polícia Militar são encarregados de Processo Administrativo Disciplinar (Sindicância), conforme está previsto na Portaria n. 028, de 07 de junho de 2001.

Outrossim, na Polícia Militar do Estado de Pernambuco [PMPE] (2017), seus integrantes: Subtenentes e Sargentos, são encarregados de sindicância, conforme previsão legal contida na Instrução Normativa n. 02 - Corregedoria Geral/SDS - de

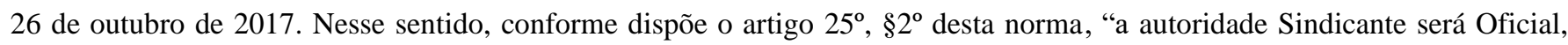
Aspirante a Oficial, Subtenente ou Sargento com Curso de Aperfeiçoamento de Sargento (CAS), respeitada, em todo caso, a precedência hierárquica em relação ao Sindicado" (PMPE, 2017).

Ademais, a Polícia Militar do Estado do Pará [PMPA] (2018), é outra coirmã em que os Subtenentes e Sargentos também são encarregados de sindicância, conforme está previsto no Boletim Geral n. 073 de 19 de abril de 2018.

Na Polícia Militar de Minas Gerais [PMMG] (2012), conforme está positivado no Manual de Processos e Procedimentos Administrativos das Instituições Militares do Estado De Minas Gerais (MAPPA), Resolução Conjunta n. 4220, de 28 de junho de 2012, no seu artigo 283, aduz que: "O sindicante deverá ser oficial, Subtenente ou Sargento, possuidor de precedência hierárquica em relação ao militar sindicado. Nos casos em que o acusado for militar da reserva, basta que o encarregado da apuração seja de mesmo posto ou graduação" (PMMG, 2012).

Isto posto, conforme pode ser observado na referida norma, que os sargentos, desde que possuidores do Curso de Aperfeiçoamento de Sargento, podem instruir Sindicância na aludida instituição castrense.

Outrossim, a Polícia Militar de Rondônia (PMRO), através do Decreto n. 13255, de 12 de novembro de 2007 (Regulamento Disciplinar da Polícia Militar do Estado de Rondônia - RDPM/RO), que trata dos Procedimentos e Processos Administrativos, conta que Sargentos aperfeiçoados também são incumbidos de Sindicância. Portanto, o artigo 24, §2 , dispõe que:

Art. 24. O processo se inicia com o memorando disciplinar, no qual a autoridade disciplinar fará constar, com a clareza e concisão indispensáveis ao entendimento, a síntese do fato e o dispositivo violado.

(...) 
$\S 2^{\circ}$ A autoridade disciplinar poderá delegar a instrução do processo, por meio de simples despacho, a oficial ou sargento, neste caso, desde que seja possuidor do curso de aperfeiçoamento (Decreto n. 13255, 2007).

Ademais, a Polícia Militar do Mato Grosso [PMMT] (2009), em seu manual de sindicância da polícia militar, relata em seu art. $3^{\circ}$ que:

Art. $3^{\circ}$ A Sindicância será iniciada de ofício ou por determinação de autoridade superior através de portaria ou ordem por escrito;

$\S 1^{\circ}$ Serão observadas as normas regulamentares de circunscrição, hierarquia e comando na Polícia Militar do Estado de Mato Grosso;

$\S 2^{\circ}$ Será designado como sindicante um Oficial PM, Aspirante - à - oficial PM, Sub - Tenentes e ou Sargentos mais antigos ou de posto ou graduação superior ao sindicado.

(...)

Conforme as normativas descritas, são muitas as instituições militares brasileiras que os Subtenentes e Sargentos são encarregados de presidir Sindicância para apurar as condutas dos seus integrantes. Logo, evidencia-se que isso ocorre em razão da necessidade da instituição e do amparo jurídico para tal.

Assim como ocorre em outros entes federativos, a administração militar tocantinense utiliza-se das normas que regem o Exército Brasileiro, mas de forma subsidiária. No artigo 176, caput, do Anexo ao Decreto n. 4994 (2014), dispõe que "Nos casos omissos, aplicam-se subsidiariamente na Corporação as normas que regem o Exército Brasileiro, no que lhe for pertinente".

Frisa-se que na administração castrense do Estado do Tocantins, pela norma vigente (Lei n. 2578, 2012), somente os Aspirantes a Oficiais e os Oficiais podem ser encarregados de presidir sindicância. Ao longo do artigo ficou esclarecido que a principal diferença entre o processo e procedimento é o fato daquele está atrelado ao princípio do contraditório e ampla defesa, assim, como o procedimento não segue este princípio, acaba sendo mais célere. Além disso, observou-se que os pesquisadores e doutrinadores brasileiros trouxeram várias lições e deixaram claro e compreensível sobre o proceder dos processos administrativos disciplinares nas instituições públicas e a importância de estarem normatizados.

Ademais, verificou-se que cada Instituição possui seus regulamentos próprios sobre matéria disciplinar, sendo que no âmbito militar o processo administrativo entre suas finalidades tem como premissa maior combater atos ilícitos e proteger a hierarquia e disciplina. Já o procedimento derivado do Poder Disciplinar tem por finalidade subsidiar decisão de Instauração de Sindicância ou Inquérito Policial Militar - IPM. No entanto, na PMTO (2012) apenas os Oficiais e Aspirantes Oficiais podem atuar como Encarregados de Sindicâncias e de Procedimento Investigatório Preliminar.

Foi realizada uma pesquisa documental na PMTO com base na ementa dos últimos Cursos de Formação de Soldados, Habilitação de Cabos, Habilitação de Sargentos e Aperfeiçoamentos de Sargentos, nos quais se constatou formação em disciplinas jurídicas, bem como específicas de Processos e Procedimentos Administrativos. Além disso, verificou-se que o graduado $1^{\circ}$ Sargento e Subtenentes da PMTO, ao longo de sua carreira, já desempenham atividades como Escrivães de Sindicância e de Inquérito Policial Militar e Auto de Prisão em Flagrante, podendo inclusive ter participação como membro titular de Conselho de Disciplina na função de Secretário e com poder de voto em mesma proporção que os demais membros, ou seja, oficiais. Portanto, infere-se que eles possuem experiência, conhecimento e capacidade para atuarem como sindicantes, de igual modo como Encarregados de Procedimento Investigatório Preliminar, que por sua natureza é mais simples e célere.

Além disso, foi verificado que algumas instituições militares brasileiras os Subtenentes e Sargentos são encarregados de sindicância. Assim, foram identificadas e apresentadas as normas das seguintes instituições militares: Exército Brasileiro (EB); Polícia Militar do Estado de Amapá (PMAP), Polícia Militar do Estado de Pernambuco (PMPE); Polícia Militar do Estado do Pará (PMPA); Polícia Militar de Minas Gerais (PMMG); Polícia Militar de Rondônia (PMRO) e Polícia Militar do 
Mato Grosso (PMMT), em que os Subtenentes e $1^{\circ}$ Sargentos aperfeiçoados são encarregados de sindicância. Vale ressaltar que em algumas dessas instituições, até os $3^{\circ}$ e $2^{\circ}$ Sargentos sem o CAS também atuam como sindicantes.

Portanto, observa-se que são muitas instituições militares brasileiras - tanto na União quanto nos Estados da federação - em que os Subtenentes e Sargentos são encarregados de sindicância. Isso ocorre porque, como foi mostrado, existe amparo legal (normas específicas) que lhes confere tal atribuição. Dessa forma, é perfeitamente cabível ser implantada esta ideia na PMTO.

Diante dos resultados deste estudo científico, propõem-se uma minuta de projeto de lei ao Poder Legislativo, propondo alteração do artigo 54, "caput", da Lei n. 2578 (2012), com o intuito de que os Subtenentes do QPPM e $1^{\circ}$ Sargentos do QPPM, aprovados com CAS da PMTO, sejam incluídos no rol dos policiais militares para atuarem como encarregados de sindicâncias. Sendo essa alteração perfeitamente aceitável, pois a própria Lei em questão menciona em seu Art. 163 que “Aplicam-se subsidiariamente na Corporação as normas que regem o Exército Brasileiro, no que lhe for pertinente" (Lei n. 2578, 2012). E como já explanado, o Exército Brasileiro já adotou essa prática.

E na sequência, necessita-se ainda de uma minuta de Decreto ao Governador, propondo alteração do $\S 3^{\circ}$, do Art. 17 , do Anexo ao Decreto n. 4994 (2014) para incluir os Subtenentes QPPM e 1 Sargentos QPPM Aperfeiçoados como Encarregados de Sindicância.

No tocante ao PIP, instituído pela Instrução Normativa n. 001/2014 - Gabinete do Comandante-Geral (PMTO, 2014), basta haver alterações no Art. $5^{\circ}$, II e Art. $7^{\circ}$, não havendo necessidade de remeter para o Poder Executivo ou Legislativo, visto que é de Competência Exclusiva do Comandante-Geral da PMTO "estabelecer e regulamentar procedimentos investigatórios sem fins punitivos no âmbito da respectiva Corporação", conforme Art. 175, Parágrafo Único (Decreto n. 4994, 2014).

Ademais, outra proposta é elaboração de uma minuta no Curso de Aperfeiçoamento de Sargentos propondo conhecimentos técnicos suficientes para que possam atuar como Encarregados de Sindicância e de Procedimento Investigatório Preliminar no âmbito da PMTO.

\section{Considerações Finais}

A presente pesquisa discorreu, descreveu, definiu, identificou e analisou o processo e procedimento administrativo disciplinar com ênfase ao que ocorre no âmbito da Polícia Militar do Estado do Tocantins.

Inicialmente foram discorridas breves noções sobre o processo administrativo brasileiro, depois sobre os aspectos do processo administrativo disciplinar, fazendo um apanhado referente aos militares estaduais e aos tipos de processos administrativos disciplinar existente na PMTO, quais sejam: Sindicância, Conselho de Disciplina e de Justificação.

Por conseguinte, aspectos históricos, conceitos, finalidades e características foram descritos referentes ao Procedimento Investigatório Preliminar - PIP. Na sequência, tratou-se sobre a carreira de praças na PMTO e as disciplinas jurídicas da matriz curricular. Depois foram identificadas algumas instituições militares brasileiras em que os Subtenentes e Sargentos aperfeiçoados atuam como encarregados de sindicância.

Nesse sentido, conclui-se que o objetivo geral foi atingido, pois a pesquisa de forma clara e objetiva cumpriu o que foi proposto nos objetivos específicos.

Atinente ao problema da pesquisa, este foi respondido e a hipótese confirmada, pois o texto constitucional autoriza que a cada ente federativo elabore seu próprio regulamento sobre processo administrativo disciplinar. Dessa forma, no presente estudo científico, foram identificadas várias instituições militares brasileiras em que os Subtenentes e Sargentos atuam como encarregados de sindicância.

Em face dessa pesquisa científica, conclui-se que consolidado está o entendimento de que os $1^{\circ}$ Sargentos aperfeiçoados e Subtenentes da Polícia Militar do Estado do Tocantins podem atuar como encarregados de sindicância, bem 
como de PIP. Assim, para que tenha respaldo legal, deixa-se propostas para que haja mudança legislativa na Lei n. 2578 (2012), concedendo-lhes tal atribuição sindicância, bem como que seja alterado dispositivo da Instrução Normativa $n$. 001/2014 - Gabinete do Comandante-Geral (PMTO, 2014) para fins de incluir esses graduados como Encarregados de PIP.

Portanto, a partir dos resultados alcançados pelo presente estudo, pretende-se não se esgotar sobre a temática em trabalhos futuros, mas colaborar para que seja de fato implantando essas atribuições na PMTO e também sirva de parâmetro para outras Corporações militares.

\section{Referências}

Assis, J. C. (2012). Direito Militar: aspectos penais, processuais penais e administrativos. (3a ed.), Ed. Juruá.

Bianchini, M. A. B. (2010). As Atividades Jurídicas dos Oficiais da Polícia Militar de Minas Gerais. [Monografia, Academia de Polícia Militar de Minas Gerais].

Brasil. (2012). Regulamento Disciplinar do Exército, das Instruções Gerais de Elaboração de Sindicância do Exército Brasileiro (EB I 0-IG-09.001). http://www.dcipas.eb.mil.br/images/Reserva/novo/eb10-ig-09.001.pdf.

Carvalho Filho, J. S. (2014). Manual de direito administrativo. (28a ed.), Atlas.

Constituição da República Federativa do Brasil de 1988. http://www.planalto.gov.br/ccivil_03/constituicao/constituicao.htm.

Decreto n. 4994, de 14 de fevereiro de 2014 (2014). Aprova o Regulamento Disciplinar dos Militares Estaduais do Tocantins - RDMETO, e adota outras providências. https://central3.to.gov.br/arquivo/179903/.

Decreto $\mathrm{n}^{\circ}$ 13225, de 13 de novembro de 2007 (2007). Aprova o Regulamento Disciplinar da Polícia Militar do Estado de Rondônia. http://www.pm.ro.gov.br/index.php/2016-02-26-13-04-45/downloads/4725-legislacoes.html.

Di Pietro, M. S. Z. (2019). Direito administrativo. (32a ed.), Ed. Forense.

Fontana, F. (2018). O projeto de pesquisa. In T. Mazucato (Org.), Metodologia da Pesquisa e do Trabalho Científico (pp. 47-53). Ed. Funepe.

Lei n. 2575, de 20 de abril de 2012 (2012). Dispõe sobre as promoções na Polícia Militar do Estado do Tocantins, e adota outras providências. https://www.al.to.leg.br/arquivos/lei_2575-2012_48501.PDF.

Lei n. 2578, de 20 de abril de 2012 (2012). Dispõe sobre o Estatuto dos Policiais Militares e Bombeiros Militares do Estado do Tocantins, e adota outras providências. https://www.al.to.leg.br/arquivos/lei_2578-2012_51345.PDF.

Manoel, É. O. (2008). Manual de Polícia Judiciária Militar. (3a ed.), Paraná.

Marconi, M. A. \& Lakatos, E. M. (2016). Fundamentos de Metodologia Científica. Ed. Atlas.

Mazucato, T. (2018). A elaboração do pré-projeto. In T. Mazucato (Org.), Metodologia da Pesquisa e do Trabalho Científico (pp. 40-46). Ed. Funepe.

Polícia Militar do Amapá. (2001). Portaria n. 028/2001. Sindicância Policial Militar. http://files.1cas2015.webnode.com/20000024618d6e19d17/SINDICÂNCIA\%20POLICIAL\%20MILITAR\%20-\%20PORT.\%20028.pdf.

Polícia Militar do Estado de Minas Gerais. (2012). Manual De Processos e Procedimentos Administrativos das Instituições Militares do Estado de Minas Gerais (MAPPA). https://policiamilitar.mg.gov.br/conteudoportal/uploadFCK/42bpm/21052013121148269.pdf.

Polícia Militar do Estado de Pernambuco (2017). Instrução Normativa n. 02 Corregedoria Geral/SDS. Dispõe sobre normas gerais procedimentais. http://www2.pm.pe.gov.br/c/document_library/get_file?p_1_id=3762505\&folderId=45769685\&name=DLFE-302920.pdf.

Polícia Militar do Estado do Mato Grosso. (2009). Manual de Sindicância Policial Militar. https://docplayer.com.br/9864507-Manual-de-sindicancia-policialmilitar-normas-tecnicas-de-elaboracao-de-sindicancia-pm.html.

Polícia Militar do Estado do Pará. (2018). Ajudância Geral. Aditamento ao BG 073. https://www.pm.pa.gov.br/sites/default/files/files/2018/ABRIL/2018.04.19-adit073.pdf.

Polícia Militar do Estado do Tocantins (2006). Diretoria de Ensino Instrução e Pesquisa. Plano de Curso de Habilitação de Sargento (CHS/2006). Palmas, TO.

Polícia Militar do Estado do Tocantins (2010). Diretoria de Ensino Instrução e Pesquisa. Plano de Curso Habilitação de Cabos (CHC/2010). Palmas, TO.

Polícia Militar do Estado do Tocantins (2014). Diretoria de Ensino Instrução e Pesquisa. Institui o Plano de Curso de Formação de Soldados (CFSD/2014). Boletim Geral n. 18. Palmas, TO.

Polícia Militar do Estado do Tocantins (2014). Instrução Normativa n. 001/2014 - Gabinete do Comandante-Geral, datada de 12 de março de 2014. Institui o Procedimento Investigatório Preliminar (PIP) no âmbito da PMTO para subsidiar a decisão de Instauração de Sindicância ou IPM. Publicada no Boletim Geral n. 049/2014. 
Research, Society and Development, v. 10, n. 9, e29510918116, 2021

(CC BY 4.0) | ISSN 2525-3409 | DOI: http://dx.doi.org/10.33448/rsd-v10i9.18116

Polícia Militar do Estado do Tocantins (2020). Diretoria de Ensino Instrução e Pesquisa. Portaria n. 025/DEIP/2020. Aprova o Plano de Curso de Aperfeiçoamento de Sargentos - CAS/2020 e adota outras providências (CAS/2020). Publicado no Boletim Geral n. 168, datado de 17 de setembro de 2020.

Silveira, D. T., \& Córdova, F. P. (2009). Unidade 2 - A pesquisa científica. In T. E. Gerhardt, \& D. T. Silveira (Orgs.), Métodos de pesquisa (pp. 31-42). Universidade Aberta do Brasil - UAB/UFRGS e pelo Curso de Graduação Tecnológica - Planejamento e Gestão para o Desenvolvimento Rural da SEAD/UFRGS. Ed. UFRGS. 